\title{
Observation of Localized Corrosion of Ni-Based Alloys Using Coupled Orientation Imaging Microscopy and Atomic Force Microscopy
}

P.J. Bedrossian, A.J. Schwartz, M. Kumar and W.E. King

U.S. Department of Energy

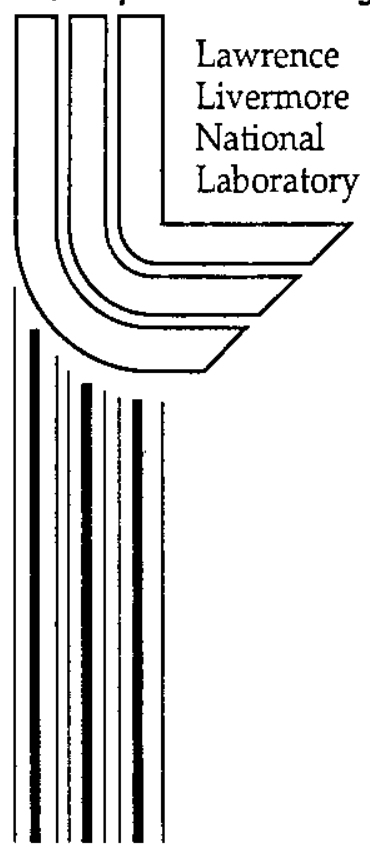

This article was submitted to

choulatido Cors

27)

Materials Research Society 1999 Fall Conference

Boston, MA

November 19-December 3, 1999

November 24, 1999 


\section{DISCLAIMER}

This document was prepared as an account of work sponsored by an agency of the United States Government. Neither the United States Government nor the University of California nor any of their employees, makes any warranty, express or implied, or assumes any legal liability or responsibility for the accuracy, completeness, or usefulness of any information, apparatus, product, or process disclosed, or represents that its use would not infringe privately owned rights. Reference herein to any specific commercial product, process, or service by trade name, trademark, manufacturer, or otherwise, does not necessarily constitute or imply its endorsement, recommendation, or favoring by the United States Government or the University of California. The views and opinions of authors expressed herein do not necessarily state or reflect those of the United States Government or the University of California, and shall not be used for advertising or product endorsement purposes.

This is a preprint of a paper intended for publication in a journal or proceedings. Since changes may be made before publication, this preprint is made available with the understanding that it will not be cited or reproduced without the permission of the author.

This report has been reproduced directly from the best available copy.

Available to DOE and DOE contractors from the Office of Scientific and Technical Information

P.O. Box 62, Oak Ridge, TN 37831

Prices available from (423) 576-8401

http://apollo.osti.gov/bridge/

Available to the public from the National Technical Information Service

U.S. Department of Commerce 5285 Port Royal Rd., Springfield, VA 22161 http://www.ntis.gov/

OR

Lawrence Livermore National Laboratory Technical Information Department's Digital Library http://www.llnl.gov/tid/Library.html 


\title{
OBSERVATION OF LOCALIZED CORROSION \\ OF NI-BASED ALLOYS \\ USING COUPLED ORIENTATION IMAGING MICROSCOPY \\ AND ATOMIC FORCE MICROSCOPY
}

\author{
PETER J. BEDROSSIAN, ADAM J. SCHWARTZ, MUKUL KUMAR, \\ AND WAYNE E. KING \\ Chemistry and Materials Science Directorate, University of California, \\ Lawrence Livermore National Laboratory, Livermore CA 94551
}

\begin{abstract}
We present a method for assessing the relative vulnerabilites of distinct classes of grain boundaries to localized corrosion. Orientation imaging microscopy provides a spatial map which identifies and classifies grain boundaries at a metal surface. Once the microstructure of a region of a sample surface has been characterized, a sample can be exposed to repeated cycles of exposure to a corrosive environment alternating with topographic measurement by an atomic force microscope in the same region in which the microstructure had been mapped. When this procedure is applied to $\mathrm{Ni}$ and Ni-based alloys, we observe enhanced attack at random grain boundaries relative to special boundaries and twins in a variety of environments.
\end{abstract}

\section{INTRODUCTION}

Advances in the engineering of grain boundaries in materials have been facilitated in recent years by the commercialization of a scanning electron microscope (SEM) technique, known as orientation imaging microscopy (OIM $\left.{ }^{\mathrm{TM}}\right)[1,2,3]$, for automated indexing of electron diffraction backscattered Kikuchi patterns (EBSP). Using the nanometer-scale resolution of an Atomic Force Microscope (AFM), it is now possible to image the surface topography associated with the incipient stages of intergranular corrosion. Therefore, if the microstructure of a particular region is mapped with OIM, then subsequent alternation of corrosion and AFM imaging will reveal relative degree of attack associated with each grain boundary type during progressive stages of corrosion. In addition, it is possible to determine whether incipient stages of pitting corrosion are correlated in any way with microstructure. The work presented below is a demonstration of the coupled application of OIM and AFM to the corrosion of Ni-containing alloys in various corrosive environments. 


\section{EXPERIMENT}

Metallographically-polished coupons of 316L stainless steel, Inconel 600, and commercially-pure, 201-grade Ni were first imaged with OIM to map their microstructures and grain-boundary orientations. $\left[{ }^{4}\right.$ Indents were made in the samples to identify the locations mapped with OIM. The OIM set-up automatically acquires and processes EBSP's for determination of local orientations, misorientations, and microtexture. The interaction of the electron beam and the specimen generates an EBSP by the backscattering of electrons from favorably oriented crystal planes. Individual orientation measurements are made at discrete points on a sample; the locations of the points are defined by a grid of dimensions prescribed by the user (both in the width and height of the grid as well as the spacing between points on the grid). At each point in the grid, the backscattered Kikuchi diffraction pattern is captured, frame averaged and automatically indexed. The three Euler angles that describe the orientation are recorded along with coordinates describing the position. Thus, images (or maps) can be generated by mapping the crystal orientation onto a color or gray scale and shading each point on the grid according to some aspect of the crystal orientation. Alternatively, misorientations between points can be indicated by drawing boundaries that are color coded by type of boundary, as for exarnple, special or random. Boundaries with $\Sigma 29$ are considered to be special while boundaries with $\Sigma>29$ are considered random.

Next, the samples were imaged with AFM in the vicinity of the indents. In each case, the as-polished surfaces had rms roughnesses below $2 \mathrm{~nm}$. From then on, exposure of the samples to aqueous, corrosive environments under open-circuit conditions was alternated with ex situ imaging of the surfaces with AFM. The presence of the indents enabled the AFM to image regions which had already had their microstructures mapped with OIM. In this way, it was possible to follow the progression of attack of individual grain boundaries. The AFM measurements were made use of a Digital Instruments DM3100 head, operated with etched silicon cantilevers in non-contact mode, in which the tip is positioned sufficiently far from the surface that the attractive region of the force curve is sampled.

\section{RESULTS}

Figure 1 displays a 75-micron AFM image and an OIM image of the same region of an electropolished surface of Inconel 600. In figure 1a and subsequent AFM images represented in three dimensions, the grey scale is associated with height in such a way that raised areas are brighter relative to depressions. In figure $1 \mathrm{~b}$ and subsequent OIM images, the random boundaries are shown in solid black, and the special boundaries are in grey. The pair of images shows that only the random boundaries were attacked discernibly. 


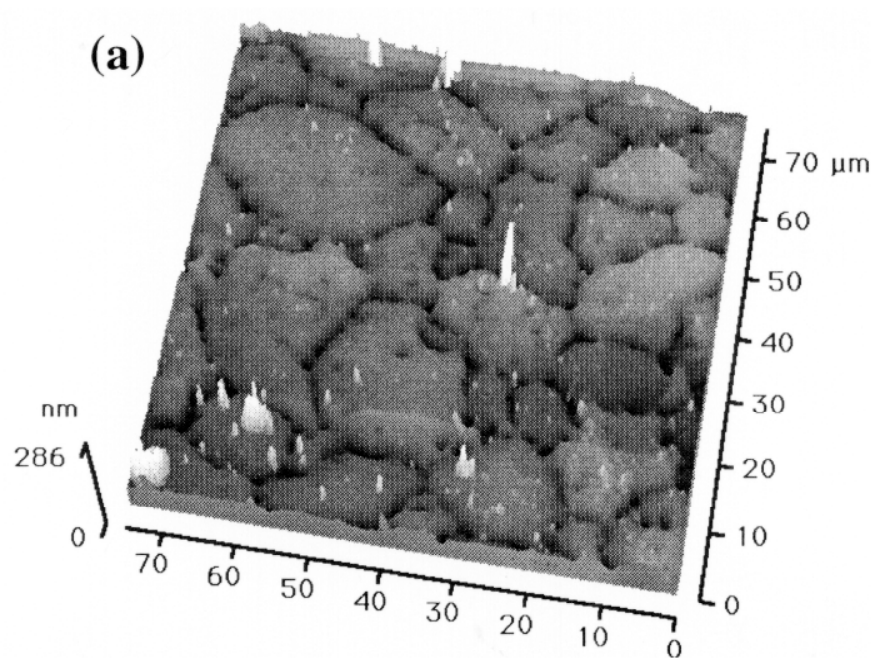

(b)

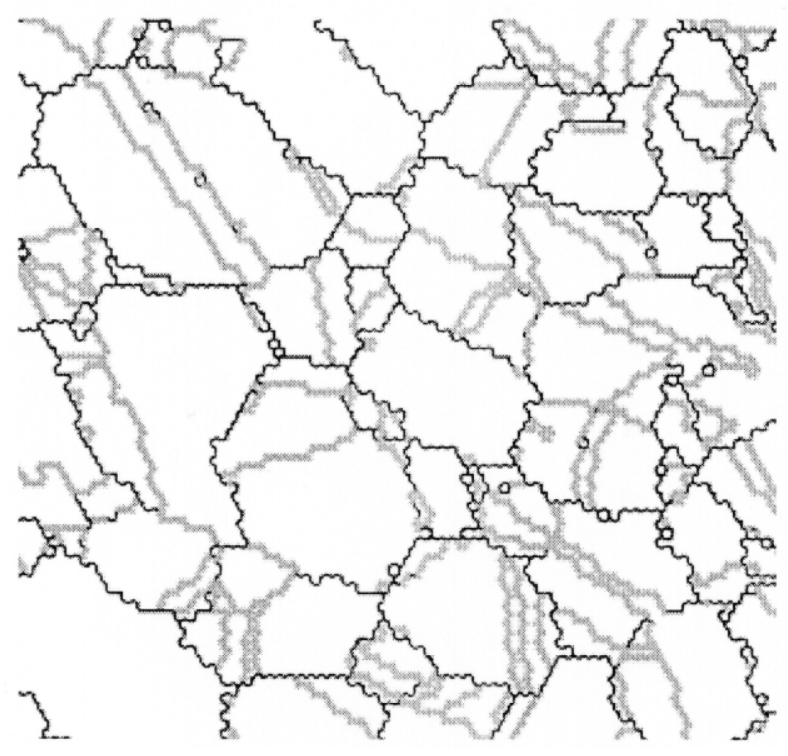

Figure 1: (a) AFM and (b) OIM images of of the same region of an electropolished Inconel 600 surface. In (a), increasing depth is shaded darker. In (b), random grain boundaries are shown in solid black, and special boundaries are grey. 

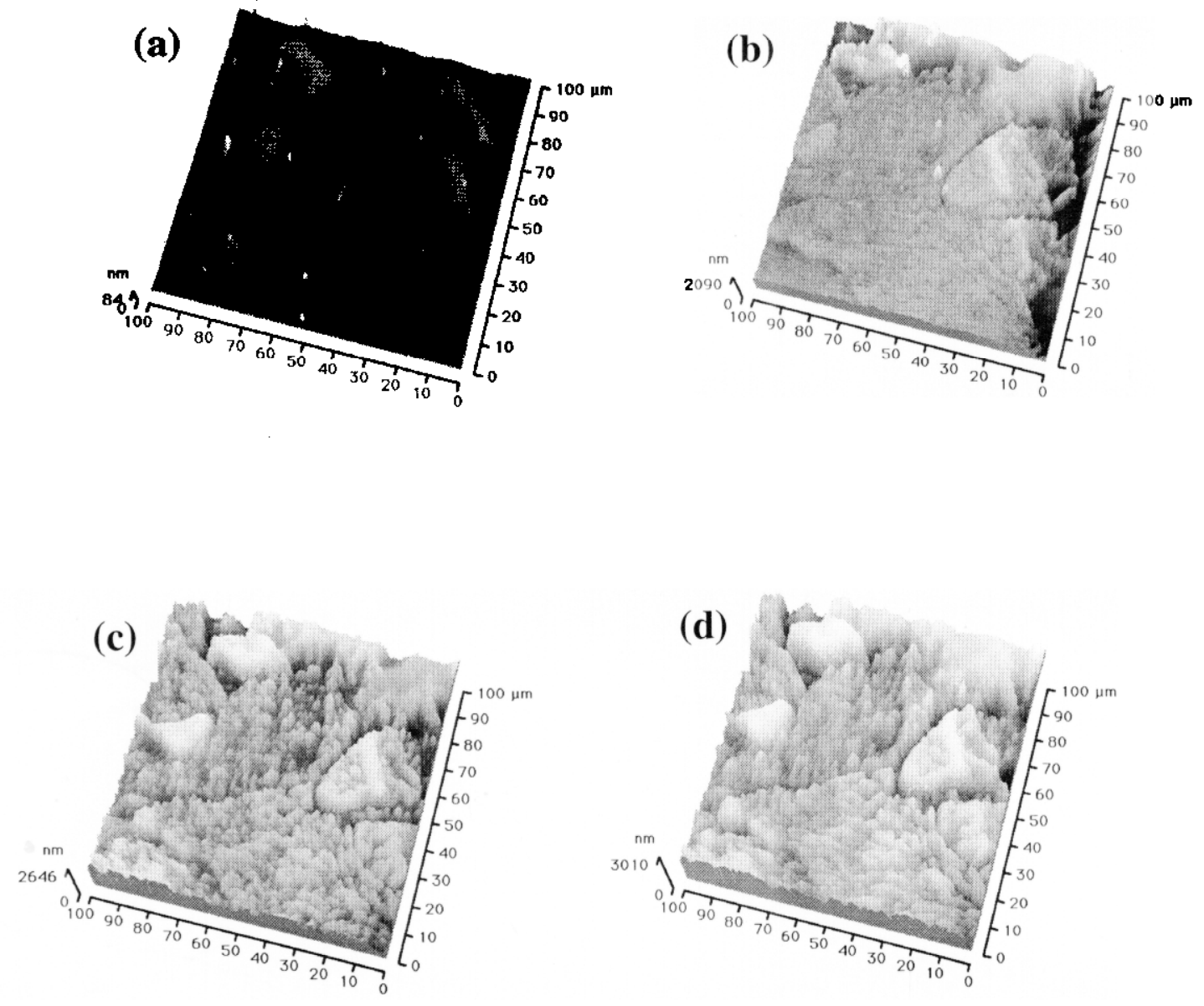

(e)

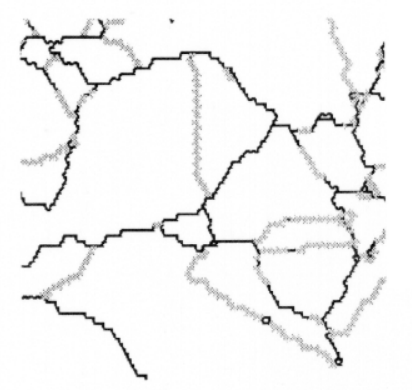

Figure 2: AFM images of the same region of an N201 nickel surface (a) as polished, and after (b) 6 hours, (c) 8 hours, and (d) 11 hours of immersion in 90C SAW; (e) Corresponding OIM image with random boundaries in black and special boundaries in grey. 
Figure 2 presents a time series of 100-micron AFM images acquired after various stages of corrosion in 90C Simulated Acidified Well Water, (SAW) which is a concentrated version of ground water extracted from Yucca Mountain, NV, with $\mathrm{pH}=2.7$. The surface was initially mechanically polished, and the OIM image of the starting surface is shown in figure 2e. Figure $2 a$ is an AFM image of the mechanically-polished surface, which shows no indication of many of the random grain boundaries which appear after the sample is immersed in the SAW. Figures $2 b, c$, and d show the same region of the surface following 6 hours, 8 hours, and 11 hours of immersion in SAW, respectively. As in Figure 1, those grain boundaries which are attacked most heavily are the random grain boundaries.

Table I: Ionic Concentrations in SAW, in ppm.

\begin{tabular}{|r|r|r|r|r|r|r|r|}
\hline $\mathrm{Ca}^{2+}$ & 58 & $\mathrm{Mg}^{2+}$ & 53 & $\mathrm{~K}^{+}$ & 4300 & $\mathrm{Na}^{+}$ & 43,000 \\
\hline $\mathrm{Si}$ & 50 & $\mathrm{SO}_{4}^{2-}$ & 40,000 & $\mathrm{Cl}^{-}$ & 27,000 & $\mathrm{NO}_{3}^{-}$ & 24,000 \\
\hline
\end{tabular}

Junctions of three or more grain boundaries are of particular interest, because attack of such junctions at the metal surface could open a one-dimensional path that could meander through the bulk metal. We have found that under certain conditions, triple junctions of three or more random grain boundaries on Alloy 22 may be more susceptible to localized attack than junctions of special boundaries.. As an example, figure 3 shows an AFM image of such a triple junction of three random grain boundaries on an initially metallographically-polished specimen of Alloy 22 , which was immersed in $2 \mathrm{M} \mathrm{HCl}$ for 1 week.

\section{CONCLUSIONS}

The combination of OIM and OFM offers a means to identify the microstructural origins of localized attack on a corroding surface, and to quantify the relative degrees attack at distinct types of grain boundaries. On three different alloys containing nickel, each exposed to a different environment, we have found that random grain boundaries exhibit enhanced vulnerability to corrosion relative to special boundaries.

Further work might investigate possibilities for engineering microstructure in order to diminish the susceptibility of the materials studied here to corrosion at grain boundaries and triple junctions. 

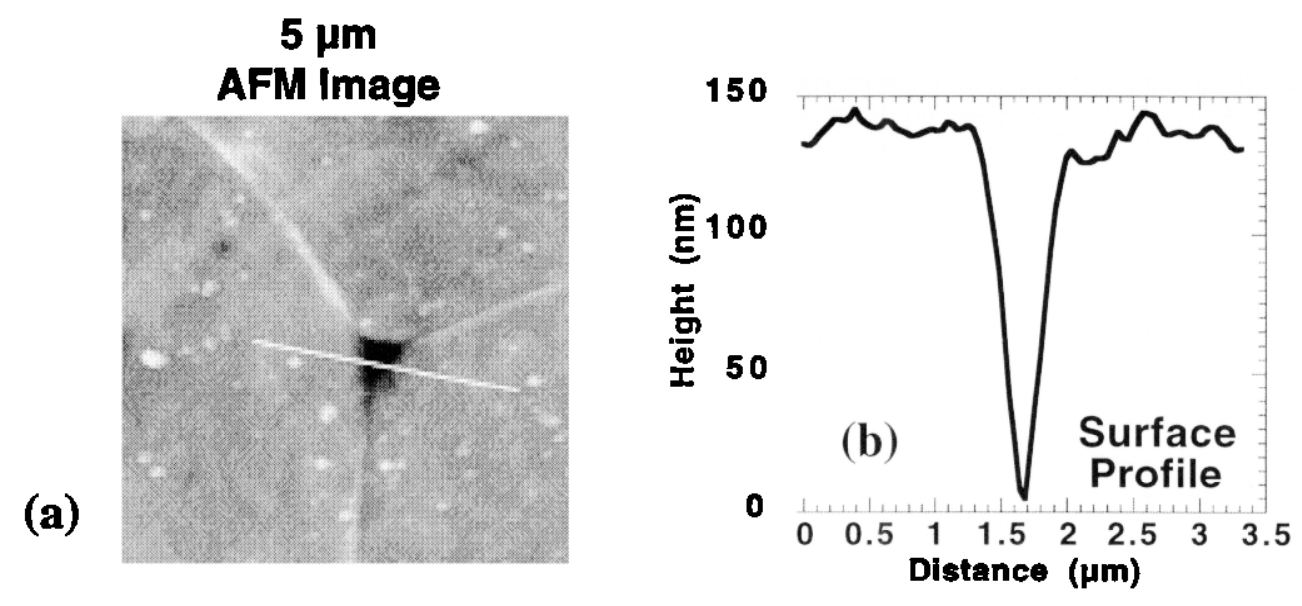

Figure 3: (a) 5-micron AFM Image of Alloy 22 exposed to $2 \mathrm{M} \mathrm{HCl}$ for 1 week, as described in the text. (b) Profile along the white line spanning the triple junction in (a).

\section{ACKNOWLEDGMENTS}

The authors are grateful to D. Fix for assistance with the AFM, and to E. Sedillo and R. Kershaw for specimen preparation.

- Work was performed at Lawrence Livermore National Laboratory under the auspices of the US DOE under Contract W-7405-Eng-48, and was partially supported by the Yucca Mountain Site Characterization Project.

\section{REFERENCES}

1. R. D. Doherty, I. Samajdar, and K. Kunze, Scripta Metall. Mater., 27, p. 1459 (1992).

2 B. L. Adams, Mater. Sci. Engg., A166, p. 59 (1993).

3 B. L. Adams, S. I. Wright, and K. Kunze, Metall. Trans., A24, p. 819 (1993).

4 The compositions of these alloys are given in J. Davis, et al., ed, ASM Handbook Volume 13: Corrosion, ASM International, Metals Park, OH, 1987, p. 664. 